\title{
Development of Aluminium Based Silicon Carbide Particulate Metal Matrix Composite
}

\author{
Manoj Singla ${ }^{1}$, D. Deepak Dwivedi ${ }^{1}$, Lakhvir Singh ${ }^{2}$, Vikas Chawla $^{3^{*}}$ \\ ${ }^{1}$ Department of Mechanical Engineering, R.I.E.I.T., Railmajra, Distt. Nawanshahr (Pb.)-144533, \\ India \\ ${ }^{2}$ Department of Mechanical Engineering, BBSBEC, Fatehgarh Sahib (Pb.), India \\ ${ }^{3}$ Department of Metallurgical \& Materials Engineering, I.I.T. Roorkee (Uttaranchal), India \\ *Corresponding Author: email: manojsingla77@gmail.com
}

\begin{abstract}
Metal Matrix Composites (MMCs) have evoked a keen interest in recent times for potential applications in aerospace and automotive industries owing to their superior strength to weight ratio and high temperature resistance. The widespread adoption of particulate metal matrix composites for engineering applications has been hindered by the high cost of producing components. Although several technical challenges exist with casting technology yet it can be used to overcome this problem. Achieving a uniform distribution of reinforcement within the matrix is one such challenge, which affects directly on the properties and quality of composite material. In the present study a modest attempt has been made to develop aluminium based silicon carbide particulate MMCs with an objective to develop a conventional low cost method of producing MMCs and to obtain homogenous dispersion of ceramic material. To achieve these objectives two step-mixing method of stir casting technique has been adopted and subsequent property analysis has been made. Aluminium (98.41\% C.P) and SiC (320-grit) has been chosen as matrix and reinforcement material respectively. Experiments have been conducted by varying weight fraction of $\mathrm{SiC}(5 \%, 10 \%, 15 \%, 20 \%, 25 \%$, and 30\%), while keeping all other parameters constant. The results indicated that the 'developed method' is quite successful to obtain uniform dispersion of reinforcement in the matrix. An increasing trend of hardness and impact strength with increase in weight percentage of $\mathrm{SiC}$ has been observed. The best results (maximum hardness 45.5 BHN \& maximum impact strength of $36 \mathrm{~N}-\mathrm{m}$.) have been obtained at 25\% weight fraction of SiC. The results were further justified by comparing with other investigators.
\end{abstract}

Key Words: Metal Matrix Composites MMC's, Silicon Carbide SiC. 


\section{INTRODUCTION}

Metal matrix composite (MMC) is engineered combination of the metal (Matrix) and hard particle/ceramic (Reinforcement) to get tailored properties. MMC's are either in use or prototyping for the space shuttle, commercial airliners, electronic substrates, bicycles, automobiles, golf clubs, and a variety of other applications.

Like all composites, aluminum-matrix composites are not a single material but a family of materials whose stiffness, strength, density, thermal and electrical properties can be tailored. The matrix alloy, reinforcement material, volume and shape of the reinforcement, location of the reinforcement and fabrication method can all be varied to achieve required properties. The aim involved in designing metal matrix composite materials is to combine the desirable attributes of metals and ceramics. The addition of high strength, high modulus refractory particles to a ductile metal matrix produces a material whose mechanical properties are intermediate between the matrix alloy and the ceramic reinforcement. Metals have a useful combination of properties such as high strength, ductility and high temperature resistance, but sometimes have low stiffness, whereas ceramics are stiff and strong, though brittle. Aluminium and silicon carbide, for example, have very different mechanical properties: Young's moduli of 70 and $400 \mathrm{GPa}$, coefficients of thermal expansion of $24 \times 10^{-6}$ and $4 \times 10^{-6} /{ }^{\circ} \mathrm{C}$, and yield strengths of 35 and $600 \mathrm{MPa}$, respectively. By combining these materials, e.g. A6061/SiC/17p (T6 condition), an MMC with a Young's modulus of $96.6 \mathrm{GPa}$ and a yield strength of $510 \mathrm{MPa}$ can be produced [1]. By carefully controlling the relative amount and distribution of the ingredients of a composite as well as the processing conditions, these properties can be further improved. The correlation between tensile strength and indentation behavior in particle reinforced MMCs manufactured by powder metallurgy technique [2]. The microstructure of SiC reinforced aluminium alloys produced by molten metal method. It was shown that stability of $\mathrm{SiC}$ in the variety of manufacturing processes available for melt was found to be dependent on the matrix alloy involved [3].

Among discontinuous metal matrix composites, stir casting is generally accepted as a particularly promising route, currently practiced commercially. Its advantages lie in its simplicity, flexibility and applicability to large quantity production. It is also attractive because, in principle, it allows a conventional metal processing route to be used, and hence minimizes the final cost of the product. This liquid metallurgy technique is the most economical of all the available routes for metal matrix composite production [4], and allows very large sized components to be fabricated. The cost of preparing composites material using a casting method is about one-third to half that of competitive methods, and for high volume production, it is projected that the cost will fall to one-tenth [5]. In general, the solidification synthesis of metal matrix composites involves producing a melt of the selected matrix material followed by the introduction of a reinforcement material into the melt, obtaining a suitable dispersion.

The next step is the solidification of the melt containing suspended dispersoids under selected conditions to obtain the desired distribution of the dispersed phase in the cast matrix. In preparing metal matrix composites by the stir casting method, there are several factors that need 
considerable attention, including the difficulty of achieving a uniform distribution of the reinforcement material, wettability between the two main substances, porosity in the cast metal matrix composites, and chemical reactions between the reinforcement material and the matrix alloy. In order to achieve the optimum properties of the metal matrix composite, the distribution of the reinforcement material in the matrix alloy must be uniform, and the wettability or bonding between these substances should be optimized. The literature review reveals that the major problem was to get homogenous dispersion of the ceramic particles by using low cost conventional equipment for commercial applications. In the present work, a modest attempt have been made to compare the dispersion of SiC particles in Al matrix fabricated with the help of different processes viz. (a) without applying stirring process (b) with manual stirring process (c) a two-step mixing method of stir casting. An effort has been made to establish a relationship between hardness, impact strength and weight fraction of $\mathrm{SiC}$ in particle reinforced MMC's developed with the help of two - step mixing method of stir casting technique.

\section{EXPERIMENTATION}

The melting was carried in a tilting oil-fired furnace in a range of $760 \pm 10^{\circ} \mathrm{C}$. A schematic view of the furnace has been shown in Figure 1.

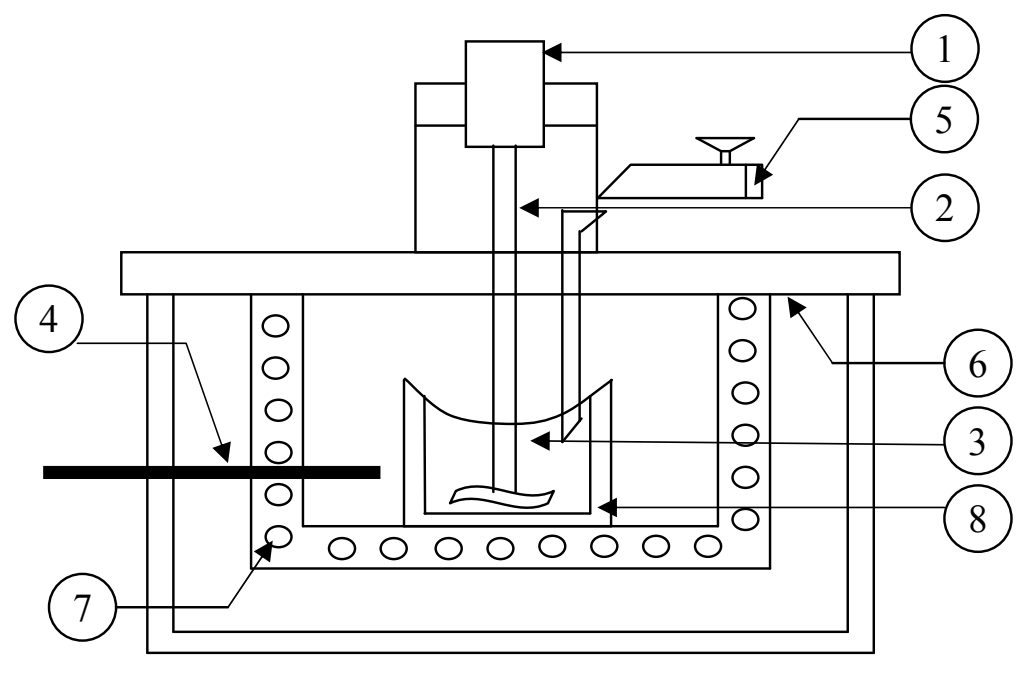

Fig. 1. Schematic view of setup for Fabrication of composite

1. Motor

2. Shaft

3. Molten aluminium

4. Thermocouple
5. Particle injection chamber

6. Insulation hard board

7. Furnace

8. Graphite crucible 
In the present study, an oil fired tilting furnace has been used. The crucible material was graphite. Diesel was used as the fuel. A forced draft fan equipped with 02 H.P 2820-rpm motor has been used for supplying the required quantity of air.

Scraps of aluminium were preheated up to a temperature of $450^{\circ} \mathrm{C}$ and particles of silicon carbide up to a temperature of $1100^{\circ} \mathrm{C}$ in core drying oven. Crucible used for pouring of composite slurry in the mold was also heated up to $760{ }^{\circ} \mathrm{C}$.

In the present study, a new stir caster was developed to fabricate MMC. It has been used to obtain an output of $600 \mathrm{rpm}$ [6]. The stir caster was mounted on the furnace with the help of four legs. Mild steel was chosen as stirrer and impeller material. During experimental work, a four bladed $45^{\circ}$ angled stirrer was chosen. The stirrer position should be such that $35 \%$ of material should be below the stirrer and $65 \%$ of material should be above the stirrer [7].

\section{METHODOLOGY}

First of all stirring system has been developed by coupling motor with gearbox and a mild steel stirrer. All the melting was carried out in a graphite crucible in an oil-fired furnace. Scraps of aluminium were preheated at $450^{\circ} \mathrm{C}$ for 3 to 4 hours before melting and mixing the $\mathrm{SiC}$ particles were preheated at $1100^{\circ} \mathrm{C}$ for 1 to 3 hours to make their surfaces oxidized.

The furnace temperature was first raised above the liquidus to melt the alloy scraps completely and was then cooled down just below the liquidus to keep the slurry in a semi-solid state. At this stage the preheated $\mathrm{SiC}$ particles were added and mixed manually. Manual mixing was used

because it was very difficult to mix using automatic device when the alloy was in a semi-solid state.

After sufficient manual mixing was done, the composite slurry was reheated to a fully liquid state and then automatic mechanical mixing was carried out for about 10 minutes at a normal stirring rate of $600 \mathrm{rpm}[6]$.

In the final mixing process, the furnace temperature was controlled within $760 \pm 10^{\circ} \mathrm{C}$. Pouring of the composite slurry has been carried out in the sand mould prepared according to the specifications for hardness, impact and normalized displacement test specimens as shown in Figures 2, 3 and 4 respectively.

\subsection{Normalized Displacement Test}

Indentation was made on hardness testing machine using a $1.587 \mathrm{~mm}$ ball indenter and a varying load was applied for 30 seconds. Five different loads of $60,100,150,187.5$ and $250 \mathrm{~N}$ have been used. The penetration depth and height of model specimen has been measured by height gauge coupled with dial indicator. The normalized displacement was calculated from following formula. The average of four readings has been reported for the results. 
Normalized displacement $=$ Indentation depth

Initial height of model specimen
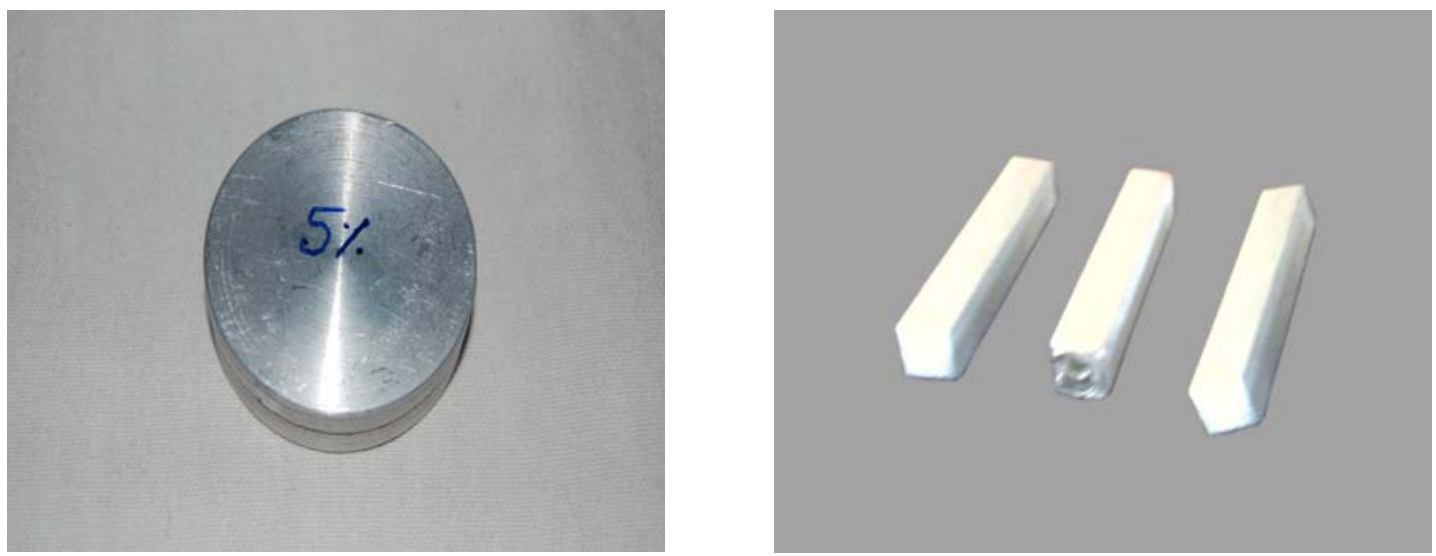

Fig. 2. Pictorial view of sample containing 5\% Fig. 3. Pictorial view of samples for impact test $\mathrm{SiC}$ by weight for hardness test

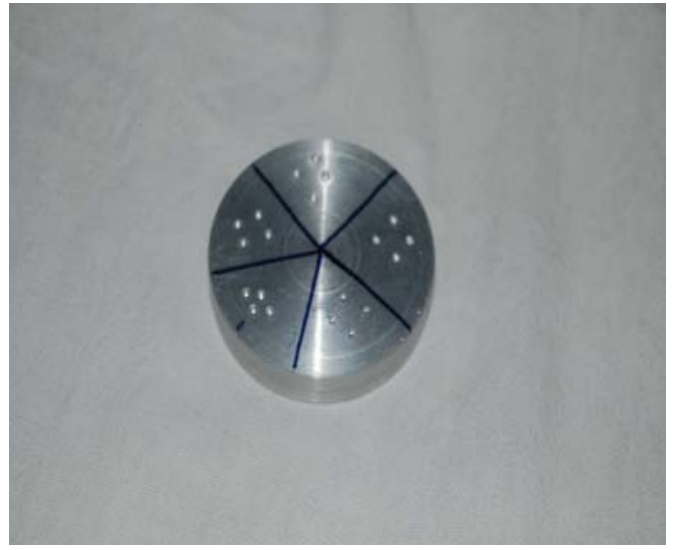

Fig. 4. Pictorial view of sample for comparing indentation load with normalized displacement.

\section{RESULTS AND DISCUSSION}

\subsection{Results}

Experiments have been conducted by varying weight fraction of $\operatorname{SiC~}(5 \%, 10 \%, 15 \%, 20 \%, 25 \%$, and 30\%). Hardness and impact strength were recorded and tabulated. Hardness test has been conducted on each specimen using a load of $250 \mathrm{~N}$ and a steel ball of diameter $5 \mathrm{~mm}$ as indenter. Diameter of impression made by indenter has been predicted by Brinnel microscope. The corresponding values of hardness $(\mathrm{BHN})$ were calculated from the standard formula. 


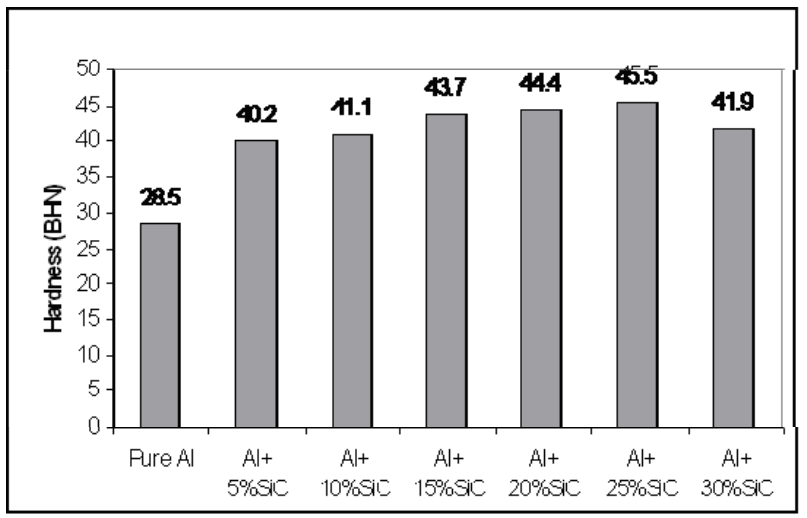

Fig. 5. Comparative bar chart (Hardness)

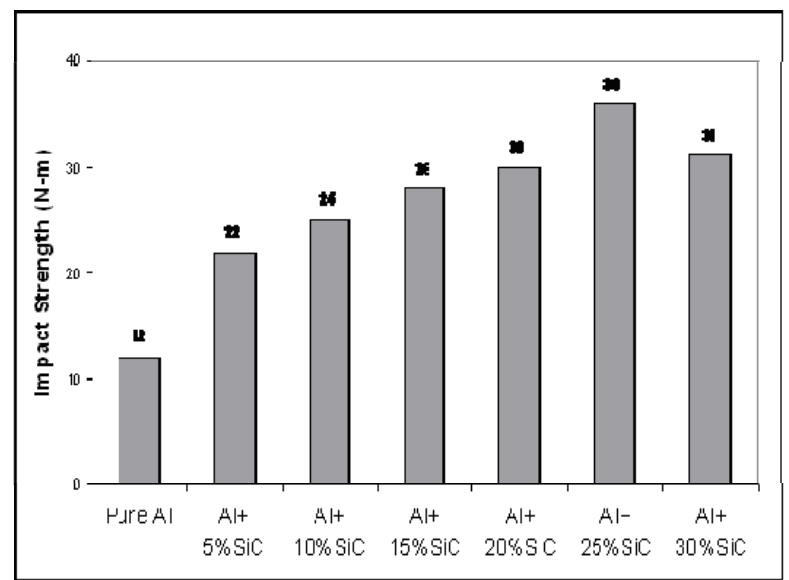

Fig. 6. Comparative bar chart (Impact Strength)

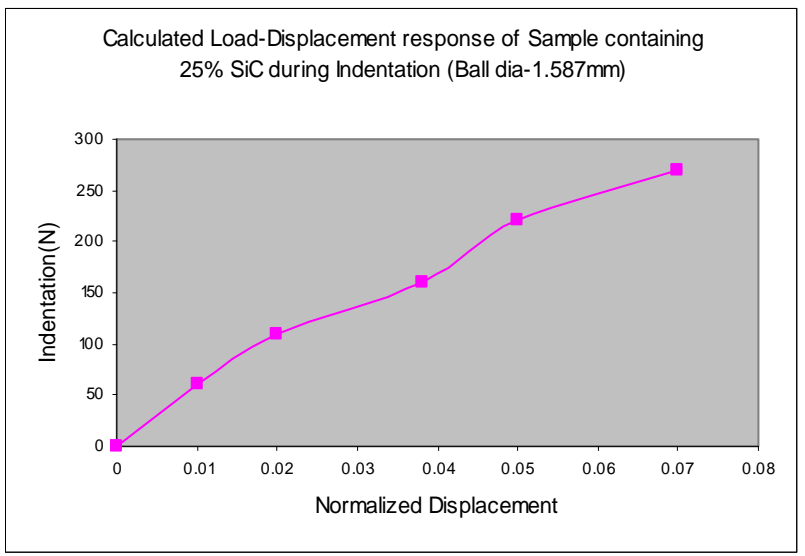

Fig. 7. Normalized displacement Vs Indentation load (For $25 \%$ SiC sample, Ball diameter $1.587 \mathrm{~mm})$

The results as indicated in Figures 5 and 6 show the increasing trend of hardness and impact strength with increase in weight percentage of $\mathrm{SiC}$ up to $25 \%$ weight fraction. Beyond this weight fraction the hardness trend started decreasing as $\mathrm{SiC}$ particles interact with each other leading to clustering of particles and consequently settling down. Eventually the density of SiC 
particles in the melt started decreasing thereby lowering the hardness. The best value of hardness and toughness comes out to be of sample containing 25\% SiC i.e. $45.5 \mathrm{BHN}$ (Hardness) and 36 $\mathrm{N}-\mathrm{m}$ (Impact Strength). The resultant samples were then examined for their hardness in terms of normalized displacement at varying loads. The Pictorial view of the sample has been shown in Figure 4.

The trends in the results have been almost similar and a maximum variation of $14.2 \%$ in the normalized displacement of indenter has been found at $250 \mathrm{~N}$ load in the sample containing $25 \%$ SiC. This was illustrated in Figure 7.

Metallographic samples were sectioned from the cylindrical cast bars. A $0.5 \%$ HF solution was used to etch the samples wherever required. To see the difference in distribution of SiC particles in the aluminum matrix, microstructure of samples were developed on Inverted type Metallurgical Microscope (Make: Nikon, Range-X50 to X1500) First sample was prepared without applying any stirring process and the second sample has been fabricated with the help of manual stirring. All other samples were developed by using two step mixing method of stir casting technique by taking varying weight fractions of $\mathrm{SiC}$ particles. The various weight fractions were $5 \%, 10 \%, 15 \%, 20 \%, 25 \%$ and $30 \%$ of $\mathrm{SiC}$ particles.

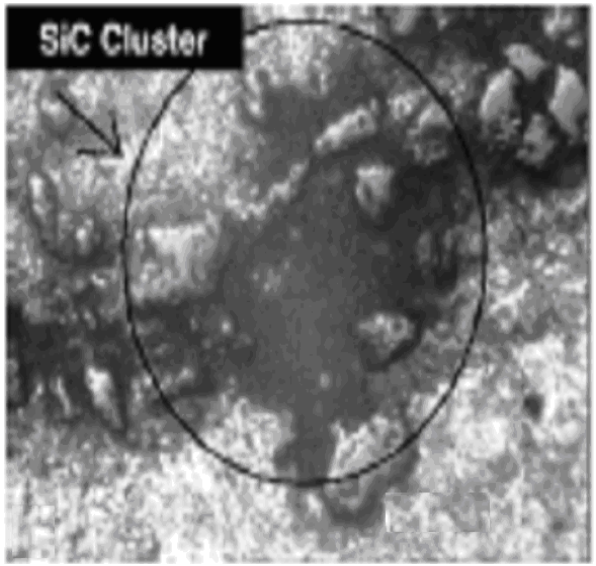

Fig. 8. Micrograph of sample obtained without stirring (100microns)

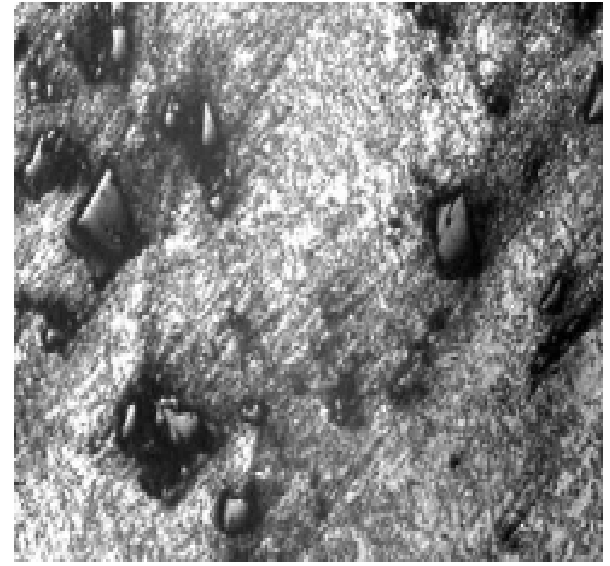

Fig. 9. Micrograph of sample obtained with manual stirring (100microns) 


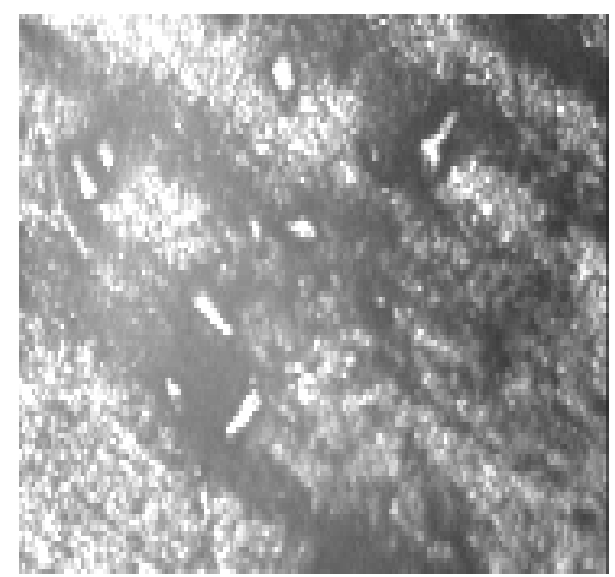

Fig. 10. Micrograph of sample containing 5\% $\mathrm{SiC}$ by weight (100microns)

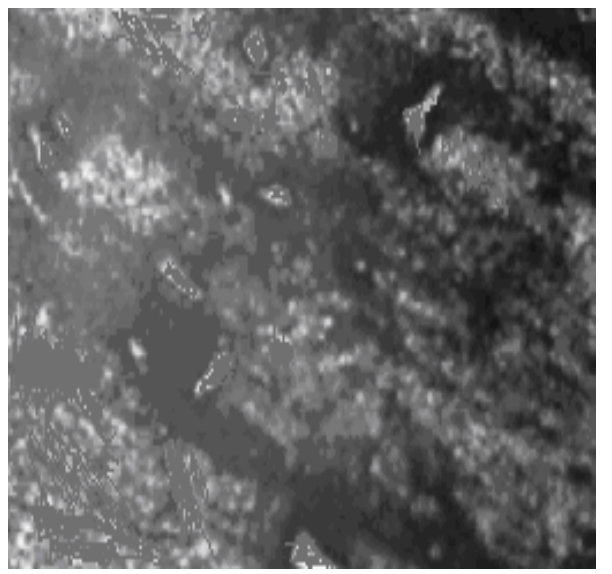

Fig. 12. Micrograph of sample containing $25 \%$ $\mathrm{SiC}$ by weight (100microns)

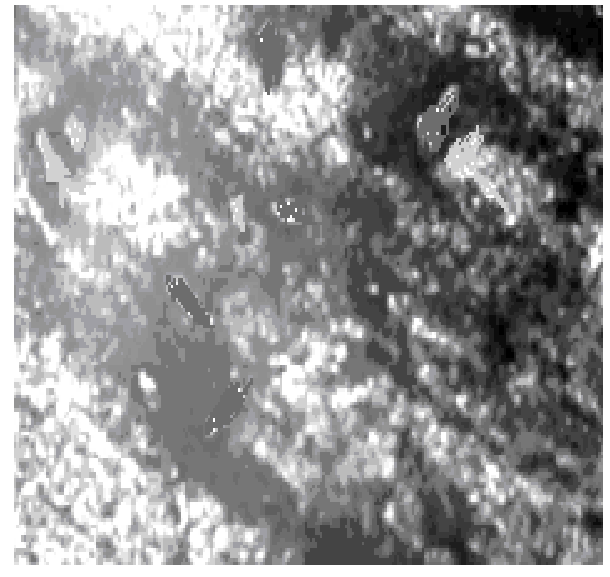

Fig. 11. Micrograph of sample containing 15\% $\mathrm{SiC}$ by weight (100microns)

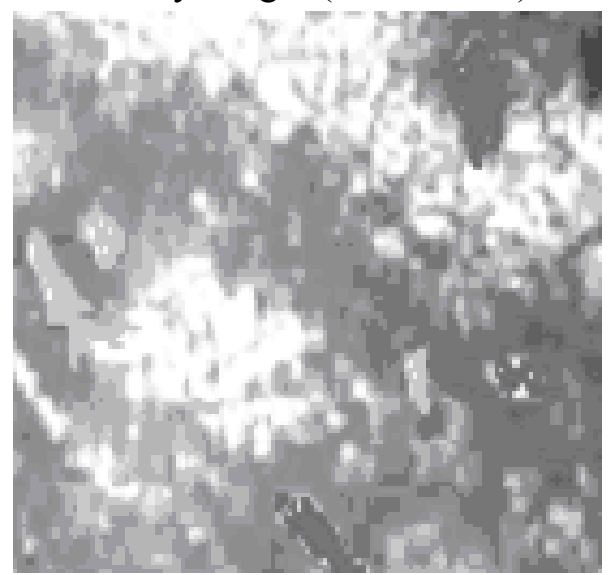

Fig. 13. Micrograph of sample containing 30\% $\mathrm{SiC}$ by weight (100microns)

\subsection{Discussions}

\subsubsection{Uniform distribution of reinforcement in the matrix}

As observed from figure 8, when the composite has been developed without applying stirring process, particle clustering occurred in some places, and some places were identified without $\mathrm{SiC}$ inclusion. This was due to the fact that when the $\mathrm{SiC}$ particles were added into the molten alloys, they were observed to be floating on the surface, though they have a large specific density than the molten metals. This was due to high surface tension and poor wetting between the particles and the melt. In fact, wettability between most ceramic particles and liquid metals has been poor. A mechanical force can usually be applied to overcome surface tension to improve wettability.

Figure 9 shows the micrograph of composite developed with the help of manual stirring. However, for the composites, manual stirring in a completely liquid state could not solve the problem of poor wetting. Manual stirring could indeed mix the particles into the melt, but when stirring stopped, the particles tended to return to the surface. Most of these particles still stuck to 
one another to remain in clusters. It is not surprising for these clusters to resurface because it might be argued that pores could exist in them to make them float. However, the fact that single particles also tended to return to the surface strongly indicates that the particles floated mainly because of the surface gas layers surrounding them [7].

The gas layers might be the main factor for the poor wettability [7]. Firstly, gas layers can cause the buoyant migration of particles, making it difficult to incorporate the particles into the melt. Secondly, even the particles can be suspended in the melt by vigorous agitation; it has been still difficult for the particles to be wetted by the molten metals because of the gas layers. The above analysis leads to the conclusion that it was necessary to break the gas layers in order to achieve good wettability. Single particles and particle clusters can flow easily in a completely liquid melt, therefore, no large mechanical forces are actually applied to the particles during agitation, making it very difficult to break the gas layers simply by stirring in the conventional way [8]. A two-step mixing method (as described before) was thus tried and was found to be effective.

In the first step, stirring has been carried out in a semi-solid state. In this state, primary $\alpha$-Al phase exists, so agitation can apply large forces on the $\mathrm{SiC}$ particles through abrasion and collision between the primary $\alpha$-Al nuclei and particles. This process can help to break the gas layers and perhaps oxide layers as well and to spread the liquid metal onto surfaces of the particles, thus helping to achieve good wettability. It was found that cast composites with upto $25 \%$ by weight particles could be obtained using this method. The advantages of using semisolid slurries have been usually considered to be the increase in the apparent viscosity and the prevention of the buoyant migration of particles.

In the present study, the breaking of particle- surface gas layers has been emphasized. When the gas layers were broken and the particles have been wetted, the particles will tend to sink to the bottom (due to higher specific weight) rather than float to the surface. However, this does not ensure a uniform particle distribution.

To improve the particle distribution, the second mixing step is needed, i.e., to heat the slurry to a temperature above the liquidus and then to stir the melts using an automatic device for 10 minutes at $600 \mathrm{rpm}$.

Figures 10, 11 and 12 depicts micrograph's of samples containing 5\%,15\%, 25\% SiC by weight respectively developed with the help of two-step mixing method of stir casting. It clearly shows the resulting homogeneous distribution of particles in the samples.

Figure 13 shows micrograph of sample containing 30\% $\mathrm{SiC}$ by weight. It was understood that density of $\mathrm{SiC}$ particles decreases inspite of an increase in concentration. This may be attributed to the fact that a this weight fraction, $\mathrm{SiC}$ particles greatly interact with each other leading to clustering of particles and consequently settling down.

\subsubsection{Hardness}


As observed from figure 4 , the hardness value increases up to $25 \%$ weight fraction of $\mathrm{SiC}$ and beyond this weight fraction the hardness trend started decreasing. In the hardness test, severe plastic flow has been concentrated in the localized region directly below the indentation, outside of which material still behaves elastically. Directly below the indentation the density of the particles increased locally, compared to regions away from the depression. This was schematically shown in figure 13. Although plastic deformation itself has not been responsible for volume change, the existence of very large hydrostatic pressure under the indentation can contribute to volumetric contraction of the metal matrix.

As the indenter moves downward during the test, the pressure has been accompanied by nonuniform matrix flow along with localized increase in particle concentration, which tends to increase the resistance to deformation. Consequently, the hardness value increases due to local increase in particle concentration associated with indentation up to $25 \%$ weight fraction of $\mathrm{SiC}$. Beyond this weight fraction the hardness trend started decreasing as $\mathrm{SiC}$ particles interact with each other leading to clustering of particles and consequently settling down. Eventually the density of SiC particles started decreasing locally thereby lowering the hardness.

\subsubsection{Micro structural features in cast composites}

Figure 8 predicts that the main micro structural features in cast composites have been in the form of dendrites. The $\mathrm{SiC}$ atoms in the crystal structure of aluminum was in solid solution, and have been distributed among the aluminum atoms in an atomic dispersion. The composites does not freeze at a single temperature but instead over a temperature range (temperature at which the freezing begins was called the liquidius, and the temperature at which freezing was complete is called the solidus) [9].

The phenomenon of dendrite structure formation may be due to supercooling effect in which certain preferred regions protrude as spikes into the supercooled regions and once started, grow more rapidly then neighboring regions. This had happened because the driving force for freezing was greater in the super cooled regions and the spikes reject the solute at their sides, thus delaying freezing of the side regions. These spikes consequently tend to form side arms producing a dendritic structure.

Figure 9 and 10 shows that clusters of SiC particles in the primary $\alpha$ - Al seemed to be finer. This can be explained by the fact that $\mathrm{SiC}$ particles have a lower thermal conductivity and heat diffusivity than those of aluminium melt and therefore, $\mathrm{SiC}$ particles were unable to cool down as the melt. As a result, the temperature of the particles was somewhat higher than liquid alloy. The hotter particles may heat up the liquid in their immediate surroundings, and thus delay solidification of the surrounding liquid alloy.

Nucleation of $\alpha$ - Al phase starts in the liquid at a distance away from the particles, where the temperature was lower. The growth of $\alpha$ - Al nuclei lead to enrichment of $\mathrm{Si}$ in the melt. The 
enrichment of $\mathrm{Si}$ in the melt around the particles leads to heterogeneous nucleation. Another effect of thermal lag was that the melt around the particles would solidify in the last stage. This would make the particles located between dendrites. In other words, the interdendritic clusters of $\mathrm{SiC}$ particles have been partly inherited from inhomogeneous distribution of particles in the original slurries. In commercially pure aluminium (without $\mathrm{SiC}$ particles), dendrites were observed to be distinctively columnar and almost randomly distributed. However in cast composites, dendrites were found to be equiaxed and in the regions with clusters of SiC particles in the primary $\alpha-\mathrm{Al}$ seemed to be finer.

Figure 11 and 12 shows the extensive growth of the dendrites. During this growth, the freely suspended $\mathrm{SiC}$ particles in the melt could either be entrapped by the dendritic front or pushed ahead by the front, depending on the velocity of the growing front and geometrical compatability between the dendrite arm spacing (DAS) and particle sizes. SiC particles were generally observed to be accumulated in the inderdendritic regions and geometrical trapping by dendrites was rarely observed. These observations suggest that the $\mathrm{SiC}$ particles were always pushed by dendrite fronts during solidification regardless of the dendritic arm spacing. Pushing of particles by dendrite fronts could almost certainly occur if they were not entrapped. The existence of SiC particles can result in instability in the growth front [9].

Figure 13 predicts the effect of mass feeding in the sample containing $30 \% \mathrm{SiC}$ by weight. The equiaxed crystals were nucleated randomly ahead of the solidifying interface, the tendency of these $\mathrm{SiC}$ particles was to sink in the liquid because of the greater density of the solid. The end result was the decrease in the density of particles locally.

\section{CONCLUSIONS}

The experimental study reveals following conclusions:

(a) The results of study suggest that with increase in composition of $\mathrm{SiC}$, an increase in hardness, impact strength and normalized displacement have been observed.

(b) The best results has been obtained at 25\% weight fraction of 320 grit size $\mathrm{SiC}$ particles. Maximum Hardness $=45.5$ BHN \& Maximum Impact Strength $=36 \mathrm{~N}-\mathrm{m}$.

(b) Homogenous dispersion of $\mathrm{SiC}$ particles in the $\mathrm{Al}$ matrix shows an increasing trend in the samples prepared by without applying stirring process, with manual stirring and with 2-Step method of stir casting technique respectively.

\section{REFERENCES}

1. S. Skolianos. Mater. Sci. Eng. A210 (1990), pp. 72-82.

2. Shen, Y.L., Williams, J.J., Piotrowski, G., Chawla, N. and Guo, Y.L. (2001), "Correlation between tensile and indentation behavior of particle reinforced metal matrix composites: a numerical and experimental study," Acta Materialia, Vol. 49 (16), pp. 32193229 . 
3. Llyod, D.J., Lagace, H., Mcleod, A. and Morris, P.L. (1989), "Microstructural aspects of aluminium silicon carbide particulate composites produced by a casting method", Materials Science and Engineering, Vol. 107, pp. 73-80.

4. $\quad$ M.K. Surappa. J. Mater. Proc. Tech. 63 (1997), pp. 325-333.

5. D.M. Skibo, D.M. Schuster, L. Jolla, Process for preparation of composite materials containing nonmetallic particles in a metallic matrix, and composite materials made by, US Patent No. 4786 467, 1988

6. Balasivanandha, S., Kaarunamoorthy, L., Kaithiresan, S. and Mohan, B. (2006), "Influence of stirring speed and stirring time on distribution of particles in cast metal matrix composite", Journal of Material Processing Technology, Vol. 171, pp. 268-273.

7. Hashim, J., Looney, L. and Hashmi, M.S.J. (2001), "The wettability of SiC particles by molten aluminum alloy”, Journal of Materials Processing Technology, Vol. 119 (1-3), pp. 324-328.

8. Hashim, J., Looney, L. and Hashmi, M.S.J. (2001), "The enhancement of wettability of $\mathrm{SiC}$ particles in cast aluminium matrix composites”, Journal of Materials Processing Technology, Vol.119 (1-3), pp. 329-335.

9. Richard A. Flinn “ Fundamentals of Metal Casting” Addisson Wesley Series in Metallurgy and Materials, pp. 11-32.

10. C.G.Kang, S.Ray and P.K.Rohatgi, Mater. Sci. Eng. A188, 193 (1994).

11. Doel.T.J.A, Lorretto.M.H and Bowen.P. (1993), "Mechanical Properties of aluminium based particulate metal matrix composites", Journal of composites, Vol. 24, pp. 270-275.

12. Gnjidi, X., Boi, D. and Mitkov, M. (2001), "The influence of SiC particles on compressive properties of metal matrix composites", Materials Characterization, Vol. 147 (2), pp. 129-138.

13. Gu, J., Zhang, X. and Gu, M. (2004), "Mechanical properties and damping capacity of $\left(\mathrm{SiC}+\mathrm{AL}_{2} \mathrm{O}_{3} \cdot \mathrm{SiO}_{2}\right) / \mathrm{Mg}$ hybrid metal matrix composite", Journal of Alloys and Compounds, Article in press.

14. Gupta, M. and Qin, S. (1997), "Effect of interfacial characteristics on the failuremechanism mode of a $\mathrm{SiC}$ reinforced $\mathrm{A} 1$ based metal-matrix composite", Journal of Materials Processing Technology, Vol. 67(1-3), pp. 94-99.

15. Kaynak, C. and Boylu, S. (2005), "Effects of SiC [particulates on the fatigue behavior of an Al-alloy matrix composite", Journal of Material \& Design, Article in press, corrected proof.

16. Kok, M. (2005), "Production and mechanical Properties of $\mathrm{AL}_{2} \mathrm{O}_{3}$ particle-reinforced 2024 aluminium alloy composites”, Journal of Materials Processing Technology, Vol. 161, pp. 381-387.

17. Lucas, J.P., Stephens, J.J. and Greulich, F.A. (1991), "The effect of reinforcement stability on composition redistribution in cast aluminium metal matrix composites", Materials Science and Engineering, Vol. 131 (2), pp. 221-230.

18. Mares, M. (2001), "Some issues on tailoring possibilities for mechanical properties of particulate reinforced metal matrix composites" Journal of Optoelectronics and Advanced Materials, Vol. 3 (1), pp. 119 - 124.

19. Naher, S., Brabazon, D. and Looney, L. (2003), "Simulation of the stir casting process", Journal of Materials Processing Technology, Vol. 143-144, pp. 567-571. 
20. Naher, S., Brabazon, D. and Looney, L. (2004), "Development and assessment of a new quick quench stir caster design for the production of metal matrix composites", Journal of Material Processing Technology, Vol. 166, pp. 430-439.

21. Nakae, H. and $\mathrm{Wu}, \mathrm{S}$. (1998), "Engulfment of $\mathrm{Al}_{2} \mathrm{O}_{3}$ particles during solidification of aluminium matrix composites", Materials Sciences and Engineering, Vol. 252 (2), pp. 232238.

22. Nesarikar, A.R., Tewari, S.N. and Graham, E.E. (1993), "Room temperature wear characteristics of Al2O3-particle-reinforced aluminum alloy composite", Materials Science and Engineering A, Vol. 147 (2), pp. 191-199.

23. Ourdjini, A., Chew, K.C. and Khoo, B.T. (2001), "Settling of silicon carbide particles in case metal matrix composites", Journal of Materials Processing Technology, Vol. 116 (1), pp. $72-76$.

24. Poole, W.J. and Charras, N. (2005), “An experimental study on the effect of damage on the stress-strain behavior for Al-Si model composites", Material Science \& Engineering, Vol. 406 (1-2), pp. 300-308.

25. Quin, S., Chen, C.and Zhang, G. (1999), "The effect of particle shape on ductility of SiC reinforced 6061 Al matrix composite”, Material Science and Engineering, Vol. 272(2), pp. 363-370.

26. Ravi, N.V. and Dwarakadasa, E.S. (2006), "Effect of matrix strength on the mechanical properties of Al-Zn-Mg/SiC composites”, Composites Part A 31, pp.1139-1145.

27. Rajnesh, T. (2005), "Synthesis and tribological characterization of in-situ cast Al-TiC composites", Journal of Wear, 259, pp. 569-576.

28. Rohatgi, P.K., Sobezak, J., Asthana, R. and Kim, J.K.(1998), "Inhomogeneities in silicon carbide distribution in stirred liquids-water model study for synthesis of composites", Materials Science and Engineering, Vol.252 (1), pp. 98-99.

29. Samuel, A.M., Liu, H. and Samuel, F.H. (1993), "On the castability of Al-Si/SiC particle reinforced metal matrix composites: Factors affecting fluidity and soundness", Composite Science and Technology, Vol. 49, Issue 1, pp.1-12.

30. Wannasin, .J. (2005), "Fabrication of metal matrix composites by a high- pressure centrifugal infiltration process", Journal of Materials Processing Technology, Vol. 169, pp. 143-149. 